\title{
Primary Mucosa-Associated Lymphoid Tissue Lymphoma in Midbrain: Case Report and Literature Review
}

\section{Yongrui Zhao}

Xuanwu Hospital Capital Medical University Department of Radiation Oncology

\section{Ronghua $\mathrm{Hu}$}

Xuanwu Hospital Capital Medical University Department of Hematology

\section{Rui Wu}

Peking University Third Hospital department of Pathology

Jiankun Xu ( $\nabla$ xjk_7563@163.com)

Xuanwu Hospital Capital Medical University Department of Radiation Oncology https://orcid.org/0000-0003-2447-6348

\section{Case report}

Keywords: Mucosa-associated lymphoid tissue lymphoma, Brain parenchyma, Radiotherapy

Posted Date: March 1st, 2021

DOI: https://doi.org/10.21203/rs.3.rs-253896/v1

License: @ (i) This work is licensed under a Creative Commons Attribution 4.0 International License. Read Full License 


\section{Abstract}

Background: Primary non-dural central nervous system (CNS) mucosa-associated lymphoid tissue (MALT) lymphoma is a rare indolent B-cell lymphoma, with only a few reported cases worldwide.

Case presentation: This report presents the treatment of MALT lymphoma developing in the midbrain. The patient received radiotherapy, and the tumour was in complete remission. We also reviewed the literature on brain parenchymal-based MALT lymphoma, including the clinical presentation, treatment options and outcomes.

Conclusions: Although there is no consensus on the optimal treatment for this rare disease, patients can respond well when treated with radiotherapy alone.

\section{Background}

Primary central nervous system lymphoma (PCNSL) is an extranodal non-Hodgkin lymphoma (NHL). Approximately $90 \%$ of PCNSL cases are diffuse large B-cell lymphomas (DLBCLs), defined as aggressive neoplasms [1]. The incidence of primary central nervous system indolent lymphoma is much lower, and marginal zone lymphoma (MZL) is comparatively the most common type. Mucosaassociated lymphoid tissue (MALT) lymphoma, also known as extranodal marginal zone lymphoma, is one subtype of MZL. It is a B-cell lymphoma originating from mucosal-associated lymphoid tissue, originally described as a low-grade lymphoma in the gastrointestinal tract by Isaacson and Wright [2].

The stomach is the most common primary site of MALT lymphoma; the salivary glands, thyroid, ocular adnexa, lungs, and breasts are other common sites [3]. Primary central nervous system MALT lymphoma is rare. Most previous case reports and case series have reported primary CNS MALT lymphoma arising in the dura mimicking meningioma or subdural haematoma [4-6]. Rare cases involving the brain parenchyma have been reported, and some patients are clinically misdiagnosed with glioma [7, 8]. There are also case reports that describe spinal or both brain and spinal involvement $[9,10]$.

Herein, we present a case of primary CNS MALT lymphoma occurring in the midbrain. To the best of our knowledge, this is the first report of midbrain MALT lymphoma. We also present a review of MALT lymphoma arising in the brain parenchyma, including the clinical presentation, treatment options and outcomes.

\section{Case Presentation}

A 33-year-old HIV-negative man visited our hospital in April 2020 with a 5-month history of left blepharoptosis and a 4-month history of right limb numbness and weakness. The patient had a 1-year history of non-insulin-dependent type 2 diabetes mellitus and tuberculosis (TB). He was receiving anti-tuberculosis treatment with rifampicin, isoniazid, ethambutol, and moxifloxacin. Laboratory evaluations revealed that the C-reactive protein (CRP) level and erythrocyte sedimentation rate (ESR) were higher than normal, and the T-SPOT-TB test was positive. A computed tomography (CT) scan, as well as a magnetic resonance imaging (MRI) scan, revealed a significantly enhanced mass of $1.9 \mathrm{~cm} \times 1.8 \mathrm{~cm}$ in size in the left midbrain (Fig 1a-c). Flaky edema could be seen around the lesion, and no signal abnormalities were noted elsewhere in the brain. Due to the relatively homogeneous enhancement of the lesion, the clinical impression was that the lesion most likely represented a lymphoma. Fluorodeoxyglucose positron emission tomography (FDG-PET) showed that the maximum standardized uptake volume (SUV) was 7.48, which matched with an enhanced lesion of the brain (Fig 1d). At the same time, a lesion in the right third fore rib was identified, and the maximum SUV was 5.70. Cerebrospinal fluid (CSF) analysis from lumbar puncture showed no abnormalities. Then, the patient underwent a stereotactic robotic biopsy of the brain and rib lesion biopsy.

The histopathological evaluation of the midbrain lesion supported a diagnosis of indolent B-cell lymphoma. The morphology indicated infiltration of low-grade B-cell lymphoma with a perivascular growth pattern (Fig 2). Immunohistochemical detection showed CD20+, CD79a+ and CD38+/- results but negativity for CD3 and CD5, the Ki-67 proliferation rate was $10 \%-20 \%$ (Fig 3). Polymerase chain reaction (PCR) analysis detected clonal rearrangement of the immunoglobulin heavy chain gene (IgH) (Fig 4). DNA sequencing indicted no mutations in the B-cell lymphoma genes, including BCL-2. The final pathological result was MALT lymphoma. The pathology of the rib was a callus formation.

Based on the pathological findings, relevant examinations were further performed. Bone marrow aspiration and biopsy with flow cytometry were normal, and ophthalmologic evaluations revealed no abnormal. However, the rapid urease test for Helicobacter pylori was positive. 
The patient received local external beam radiotherapy without chemotherapy, and target delineation was based on the fusion image obtained from simulated CT and MRI. The gross target volume (GTV) was defined on MRI and PET, excluding the edema zone. The planning gross target volume (PGTV) was the GTV plus $3 \mathrm{~mm}$ of setup margin. Initially, we intended to administer a radiotherapy dose of $24 \mathrm{~Gy}$, but re-examination by MRI showed residual lesion during the treatment course after $20 \mathrm{~Gy}$ was administered. We added $6 \mathrm{~Gy}$ to the total dose of $30 \mathrm{~Gy}$. One month after radiotherapy, follow-up MRI showed no abnormal enhancement, and perfusion-weighted imaging (PWI) showed no hyperperfusion (Fig 5). After 4 months of follow-up, the patient's clinical symptoms significantly improved, and follow-up data showed no recurrence.

\section{Discussion}

Marginal zone lymphoma is a non-Hodgkin lymphoma arising from postgerminal centre marginal zone B cells. According to the 2016 World Health Organization (WHO) classification, MZL is subdivided into three types: extranodal MZL or MALT lymphoma, nodal MZL and splenic MZL [11].MALT lymphoma is the most typical type, but primary CNS MALT lymphoma is an extremely rare entity, especially in the brain parenchyma. Initial studies showed that the most common location was the dura [12]. Only 7 cases with brain parenchyma involvement have been reported, including our patient. The site of origin was the midbrain in our patient. The lesion location and clinical characteristics of the other 6 patients are shown in Table 1. Clinical symptoms are not specific, depending on the site of the lesion.

The CNS has no mucosa or lymphoid tissue, and dural-based MALT lymphoma can be explained by the embryological analogy that meningothelial cells of the arachnoid membrane could be analogous to epithelial cells, where MALT lymphomas arise [16]. However, non-dural-based MALT lymphoma is questionably explained by this theory. It is currently believed that the aetiology of MALT lymphoma is related to chronic immune stimulation caused by infection or inflammation. For instance, gastric MALT lymphoma is associated with Helicobacter pylori, Sjögren syndrome or Hashimoto thyroiditis and carries a significant risk for the development of MZL [17].

Interestingly, our patient had a 1-year history of tuberculosis and received standardized anti-tuberculosis treatment. After admission, the Helicobacter pylori examination was positive, and the patient also underwent Helicobacter pylori eradication therapy. The pathogenesis may be explained by the inflammation-based theory. However, we have no direct evidence that primary CNS MALT lymphoma is associated with Mycobacterium tuberculosis or Helicobacter pylori infection.

The diagnosis of MALT lymphoma should be confirmed by histopathological and immunohistochemical features. Differential diagnoses include lymphoplasmacytic lymphoma (LPL) and follicular lymphoma. The immunohistochemistry results of follicular lymphoma usually indicate positivity for CD10 and Bcl-2 [18]. LPL and MALT Iymphoma have similar morphological and immunohistochemical profiles, but relative to MALT lymphoma, LPL typically involves the bone marrow and is associated with Waldenstrom's macroglobulinemia [19]. Our patient's immunohistochemical findings indicated CD20+ and CD79a+ results, without bone marrow involvement, and no clinical history of Waldenstrom's macroglobulinemia. At the same time, clonal rearrangement of IgH was detected by PCR. According to these findings, the diagnosis was most consistent with MALT lymphoma.

MALT lymphoma tends to be indolent. There is no standard treatment for CNS MALT lymphoma. The treatment modalities reported in the existing literature include surgery, radiotherapy, and chemotherapy. As shown in Table 1, among patients with lesions arising from the brain parenchyma, 3 of the 6 patients received chemotherapy: two patients had stable disease, one patient showed tumour remission, the other 3 patients received radiotherapy and had a complete response. MALT lymphoma is radiosensitive. In 2011, a randomized phase III trial reported that there was no difference in clinical efficacy between the radiotherapy dose of 24 Gy and 40-45Gy for indolent NHL [20]. Currently, reduced-dose (24-30 Gy) radiotherapy is preferred for indolent lymphoma. Unlike high-grade CNS lymphoma, the role of intrathecal chemotherapy or systemic chemotherapy currently remains unclear in low-grade CNS lymphoma [21]. Because of the particularity of the lesion location, our patient could not be totally resected by surgery and achieved complete remission by radiotherapy alone. Involved-site radiation therapy (ISRT) is an effective initial treatment for extranodal marginal zone lymphoma [22]. The radiation field in our case included only the primary lesion demonstrated on MRI and PET, not as reported in the prior literature $[7,8,13]$. Reexamination during treatment showed residual disease, so we believed that one month after the end of radiotherapy might be the best time to evaluate the effect.

\section{Conclusion}

In conclusion, primary non-dural CNS MALT lymphoma is a rare disease. The exact mechanism is still unclear presently. Diagnosis is based on morphological and immunohistochemical findings. It is radiosensitive and can be cured with radiotherapy. Chemotherapy alone cannot achieve good treatment outcomes. Due to the small number of cases, it is difficult to draw conclusions regarding the use

Page 3/8 
of radiotherapy as the primary treatment for brain parenchymal-based MALT lymphoma. More clinical data are needed to confirm this opinion.

\section{Abbreviations}

CNS: Central nervous system; MALT: Mucosa-associated lymphoid tissue; PCNSL: Primary central nervous system lymphoma; NHL: NonHodgkin lymphoma; DLBCLs: Diffuse large B-cell lymphomas; MZL: Marginal zone lymphoma; TB: Tuberculosis; CRP: C-reactive protein; ESR: Erythrocyte sedimentation rate; CT: Computed tomography; MRI: Magnetic resonance imaging; FDG-PET: Fluorodeoxyglucose positron emission tomography; SUV: Standardized uptake volume; CSF: Cerebrospinal fluid; IgH: Immunoglobulin heavy chain gene; GTV: Gross target volume; PGTV: Planning gross target volume; PWI: Perfusion-weighted imaging; WHO: World health organization; LPL: Lymphoplasmacytic lymphoma; ISRT: Involved-site radiation therapy

\section{Declarations}

\section{Acknowledgements}

We acknowledge the work of colleagues in the Pathology and Radiology Department in offering the original images and data related to this article.

\section{Authors' contributions}

ZY carried out the literature search and image and data collection, and drafted the article. HR collected important background information. WR performed image processing. XJ made substantial contributions to the manuscript, including revising it critically for intellectual content. All authors read and approved the final manuscript.

\section{Funding}

Supported by Beijing Natural Science Foundation (7164308), National Natural Science Foundation of China (81601997).

\section{Availability of data and materials}

The datasets used and analyzed during the current study are available from the corresponding author on reasonable request.

\section{Ethics approval and consent to participate}

The study was reviewed and approved by Xuanwu Hospital, Capital Medical University.

\section{Consent for publication}

Informed consent was obtained from the patient for the publication of this case report.

\section{Competing interests}

We have no competing interests.

\section{References}

1. Batchelor TT. Primary central nervous system lymphoma: A curable disease. Hematological Oncology. 2019; 37(S1):15-18.

2. Isaacson $P$ and Wright DH. Malignant Lymphoma of Mucosa-Associated Lymphoid Tissue. A Distinctive Type of B-Cell Lymphoma. Cancer. 1983; 52:1410-1416.

3. Khalil MO, Morton LM, Devesa SS, et al. Incidence of marginal zone lymphoma in the United States, 2001-2009 with a focus on primary anatomic site. Br J Haematol. 2014; 165:67-77.

4. Razaq W, Goel A, Amin A, Grossbard ML. Primary Central Nervous System Mucosa-Associated Lymphoid Tissue Lymphoma: Case Report and Literature Review. Clinical Lymphoma \& Myeloma. 2009; 9(3):E5-9.

5. Jesionek-Kupnicka D, Smolewski P, Kupnicki P, et al. Primary extranodal marginal zone B-cell lymphoma of the mucosa-associated lymphoid tissue type in the central nervous system (MZL CNS) presented as traumatic subdural hematoma and subarachnoid 
bleeding-case report. Clinical Neuropathology. 2013; 32(5):384-392.

6. Choi JY, Chung JH, Park YJ, et al. Extranodal Marginal Zone B-Cell Lymphoma of Mucosa-Associated Tissue Type Involving the Dura. Cancer Research and Treatment. 2016; 48(2):859-863.

7. Aqil B, Rouah E, Verstovsek G. Primary CNS marginal zone lymphoma: a case report and review of the literature. Open J Pathol. 2013; 3:55-59.

8. Park I, Huh J, Kim JH, Lee SW, Ryu MH, Kang YK. Primary central nervous system marginal zone B-cell lymphoma of the basal ganglia mimicking low-grade glioma: a case report and review of the literature. Clin Lymphoma Myeloma. 2008; 8:305-308.

9. Ahmadi SA, Stephan F, Hänggi Daniel, Eicker SO. Primary spinal marginal zone lymphoma: case report and review of the literature. Neurosurgery. 2012; 71:E495-508.

10. Ueba T, Okawa M, Abe H, et al. Central nervous system marginal zone B-cell lymphoma of mucosa-associated lymphoid tissue type involving the brain and spinal cord parenchyma. Neuropathology. 2013; 33:306-311.

11. Swerdlow SH, Campo E, Pileri SA, et al. The 2016 revision of the World Health Organization classification of lymphoid neoplasms. Blood. 2016; 127:2375-2390.

12. Sunderland AJ, Steiner RE, Zahrani MA, et al. An international multicenter retrospective analysis of patients with extranodal marginal zone lymphoma and histologically confirmed central nervous system and dural involvement. Cancer Med.2020; 9(2):663670.

13. Tu PH, Giannini C, Judkins AR, et al. Clinicopathologic and genetic profile of intracranial marginal zone lymphoma: a primary lowgrade CNS lymphoma that mimics meningioma. J Clin Oncol. 2005; 23:5718-5727.

14. Papanicolau-Sengos A, Wang-Rodriguez J, Wang HY, et al. Rare case of a primary non-dural central nervous system low grade B-cell lymphoma and literature review. Int J Clin Exp Pathol. 2012; 5:89-95.

15. Schiefer Al, Vastagh I, Molnar MJ, et al. Extranodal marginal zone lymphoma of the CNS arising after a long-standing history of atypical white matter disease. Leuk Res. 2012; 36: e155-157.

16. Kumar S, Kumar D, Kaldjian EP, Bauserman S, Raffeld M, Jaffe ES. Primary low-grade B-cell lymphoma of the dura: a mucosa associated lymphoid tissue-type lymphoma. Am J Surg Pathol. 1997; 21: 81-87.

17. Zucca E, Bertoni F, Vannata B, Cavalli F. Emerging role of infectious etiologies in the pathogenesis of marginal zone B-cell lymphomas. Clin Cancer Res. 2014; 20:5207-5216.

18. Freedman A, Jacobsen E. Follicular lymphoma: 2020 update on diagnosis and management. American Journal of Hematology. 2020; 95(3):316-327.

19. Owen RG, Treon SP, Al-Katib A, et al. Clinicopathological definition of Waldenstrom's macroglobulinemia: consensus panel recommendations from the Second International Workshop on Waldenstrom's Macroglobulinemia. Semin Oncol. 2003; 30: 110-115.

20. Lowry L, Smith P, Qian W, et al. Reduced dose radiotherapy for local control in non-Hodgkin lymphoma: a randomised phase III trial. Radiotherapy \& Oncology Journal of the European Society for Therapeutic Radiology \& Oncology, 2011, 99(1):86-92.

21. Ayanambakkam A, Ibrahimi S, Bilal K, Cherry MA. Extranodal marginal zone lymphoma of the central nervous system. Clin Lymphoma Myeloma Leuk. 2018; 18(1):34-37.

22. Teckie S, Qi S, Chelius M, et al. Long-term outcome of 487 patients with early-stage extra-nodal marginal zone lymphoma. Ann Oncol.2017; 28:1064-1069.

\section{Table}


Table 1.

Clinical summary of patients with primary non-dural CNS MALT Iymphoma.

\begin{tabular}{|c|c|c|c|c|c|c|}
\hline Reference & $\operatorname{Age}(y)$ & Sex & Location & Presentation & Treatment & Outcome \\
\hline Tu et al [13]. & 66 & M & $\mathrm{R}$, frontal & Seizures & Radiation(WBRT, dose NA) & $\mathrm{CR}$ \\
\hline $\begin{array}{l}\text { Park et al } \\
\text { [8]. }\end{array}$ & 18 & $\mathrm{M}$ & $\begin{array}{l}\text { L, basal } \\
\text { ganglia }\end{array}$ & $\begin{array}{l}\text { Right-sided } \\
\text { central } \\
\text { facial nerve } \\
\text { palsy, right- } \\
\text { sided } \\
\text { weakness, } \\
\text { dizziness, } \\
\text { dysarthria }\end{array}$ & Radiation $(\mathrm{CTV}=\mathrm{GTV}+15 \mathrm{~mm}, \mathrm{PTV}=\mathrm{CTV}+5 \mathrm{~mm} ; 30.6 \mathrm{~Gy} / 17 \mathrm{~F})$ & $\mathrm{CR}$ \\
\hline $\begin{array}{l}\text { Papanicolau } \\
\text { et al [14]. }\end{array}$ & 70 & M & $\begin{array}{l}\text { L, } \\
\text { posterior } \\
\text { putamen }\end{array}$ & $\begin{array}{l}\text { Right } \\
\text { extremity } \\
\text { numbness, } \\
\text { dysarthria, } \\
\text { blurry vision }\end{array}$ & $\begin{array}{l}\text { Chemotherapy (dexamethasone, temozolamide, } \\
\text { rituximab) }\end{array}$ & SD \\
\hline $\begin{array}{l}\text { Schiefer } \\
\text { et al [15]. }\end{array}$ & 39 & $\mathrm{~F}$ & $\mathrm{R}$, frontal & Seizures & $\begin{array}{l}\text { Chemotherapy (intrathecal: } \\
\text { methotrexate,cytarabin,dexamethasone;Intravenous: high- } \\
\text { dose methotrexate) }\end{array}$ & SD \\
\hline Aqil et al [7]. & 48 & $\mathrm{M}$ & $L$, frontal & $\begin{array}{l}\text { Seizures, } \\
\text { memory } \\
\text { loss }\end{array}$ & Radiation(WBRT,24Gy;GTV boosted 6Gy) & $\mathrm{CR}$ \\
\hline $\begin{array}{l}\text { Ueba } \\
\text { et al [10]. }\end{array}$ & 53 & M & $\begin{array}{l}\text { R, } \\
\text { temporal; } \\
\text { L, } \\
\text { occipital; } \\
\text { spinal } \\
\text { cord }\end{array}$ & $\begin{array}{l}\text { Recent } \\
\text { memory } \\
\text { disturbance, } \\
\text { gait } \\
\text { disturbance, } \\
\text { urinary } \\
\text { incontinence }\end{array}$ & Chemotherapy (high-dose methotrexate, cytoarabine) & PR \\
\hline
\end{tabular}

Abbreviations: WBRT, whole brain radiation therapy; CTV, clinical target volume; GTV, gross target volume; PTV, planning target volume; $\mathrm{CR}$, complete remission; $\mathrm{PR}$, partial remission; SD, stable disease; NA, not available.

\section{Figures}
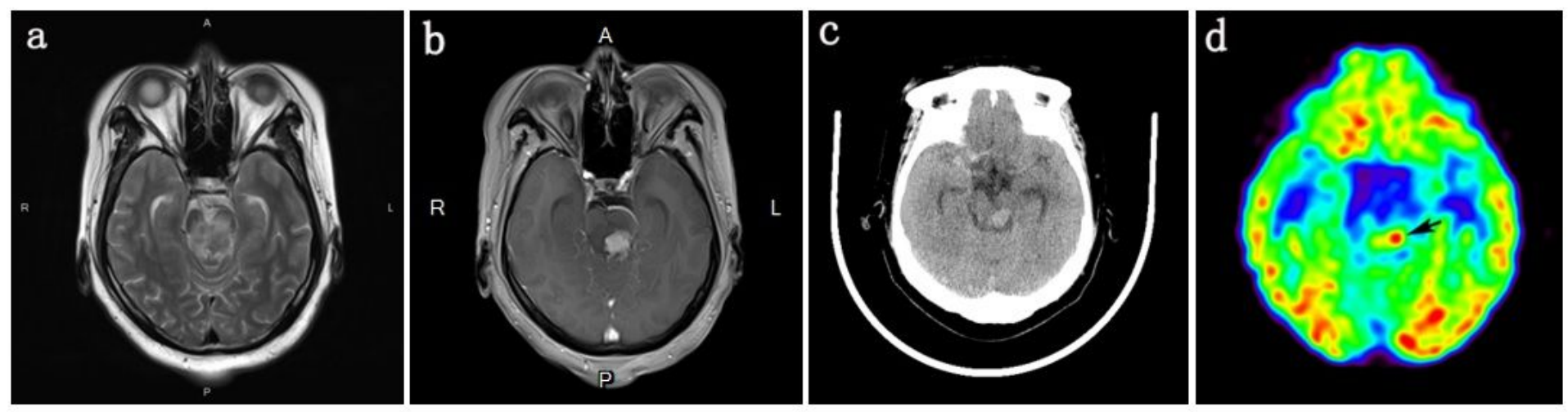

Figure 1

a. Axial T2-weighted image shows heterogeneous intensity in midbrain, midbrain aqueduct is compressed. b. Contrast-enhanced MRI shows a significant enhancing $1.9 \mathrm{~cm} \times 1.8 \mathrm{~cm}$-sized mass in the left midbrain. $\mathrm{c}$. The lesion is high density on CT. $\mathrm{d}$. FDG-PET shows the lesion is increased glucose uptake (arrow). The SUVmax is 7.48. 

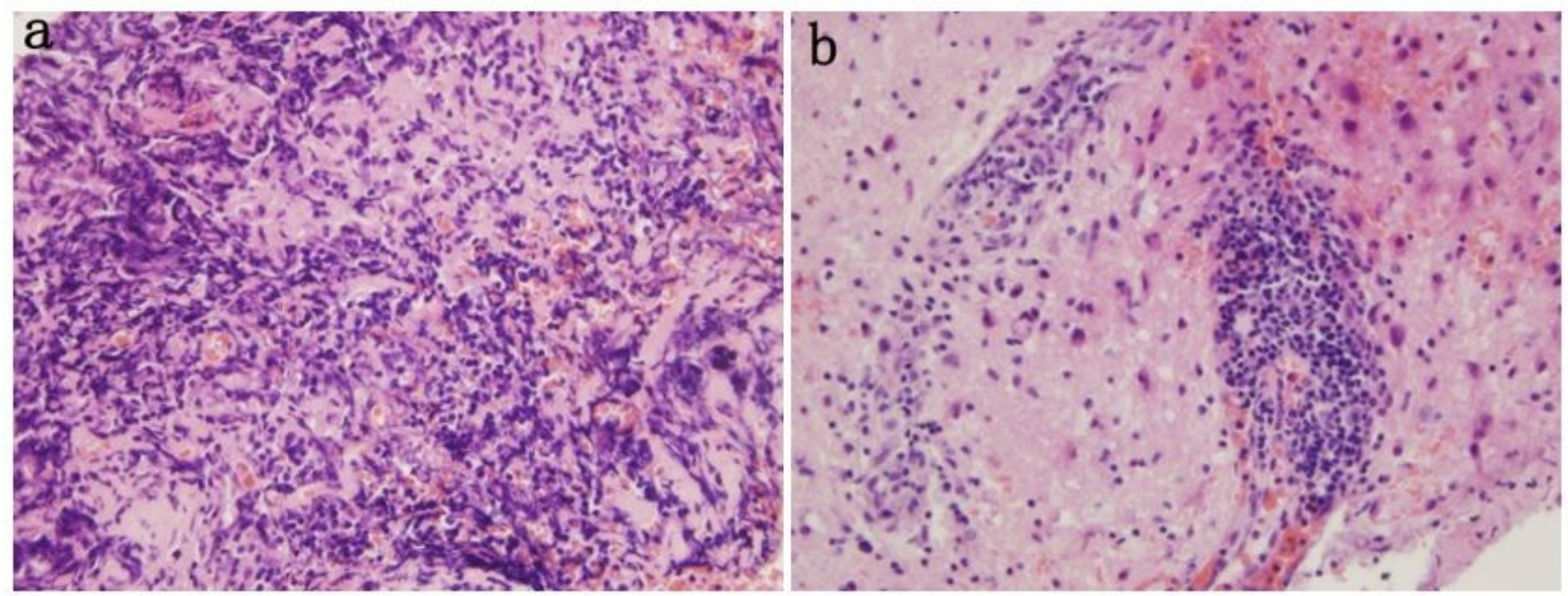

\section{Figure 2}

Histologic features. The biopsy shows perivascular infiltrates of small-sized lymphocytes. Hematoxylin and eosin (H \& E) stain, 20×(a) and $40 \times(b)$.
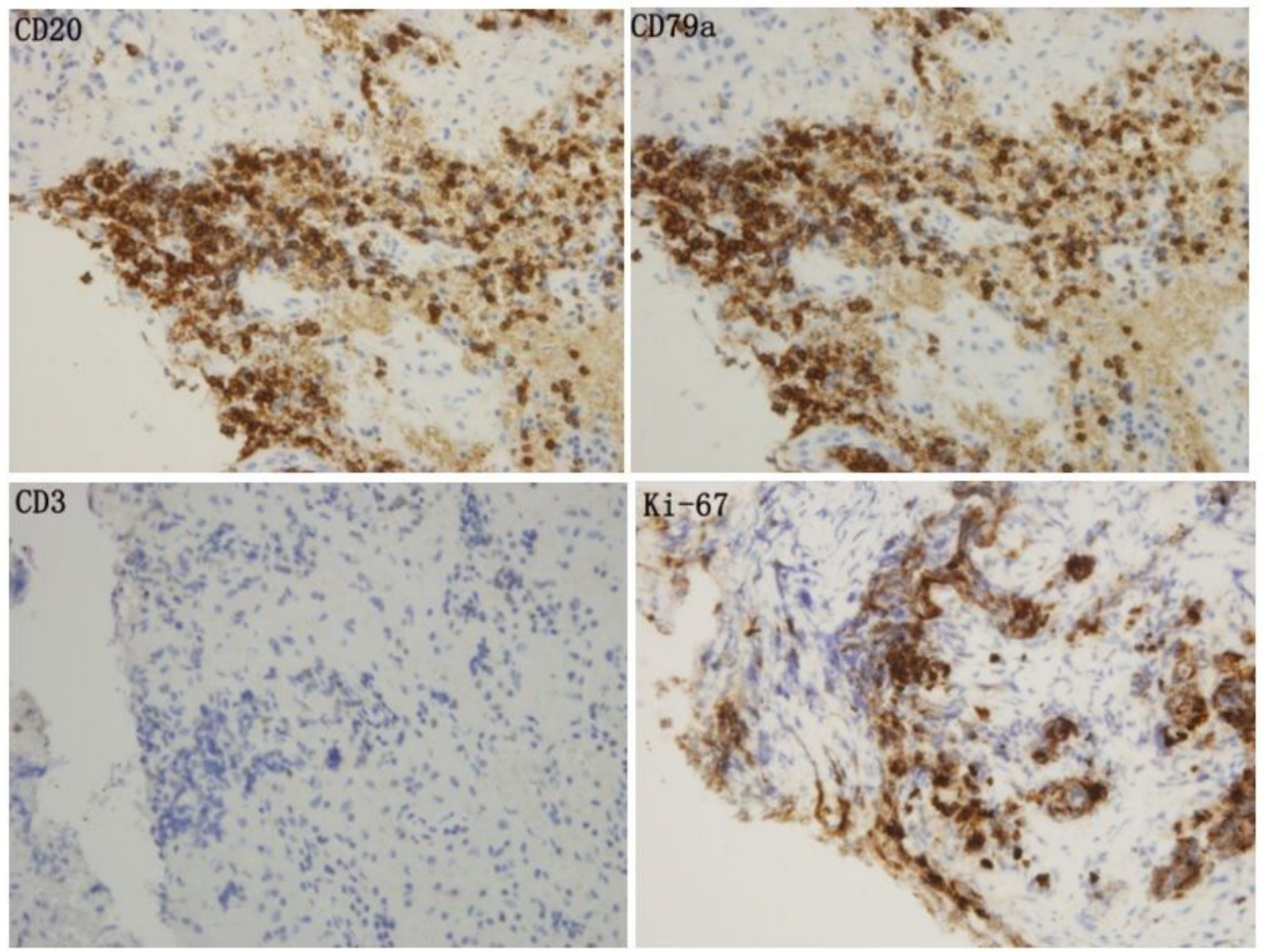

\section{Figure 3}

Immunohistochemical features. The tumor cells are positive stainings for B-lymphocyte marker CD20/CD79a and negative for Tlymphocyte marker CD3. $10 \%-20 \%$ of the cells are reactive with Ki- 67. 

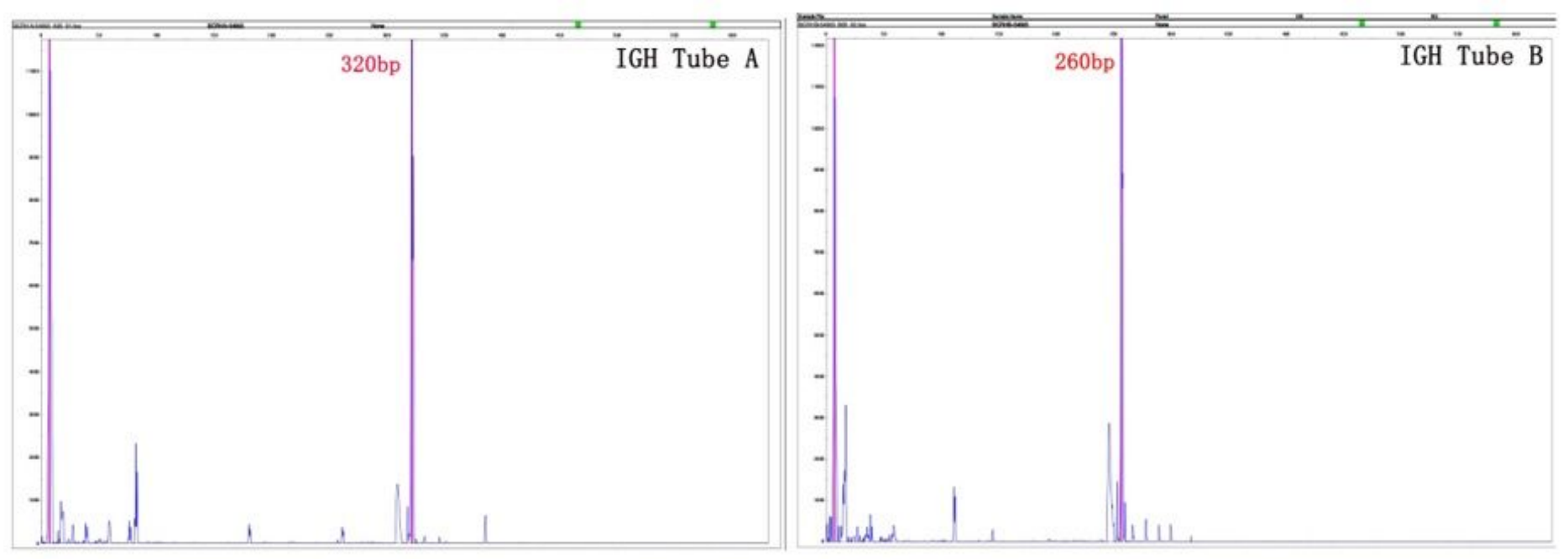

\section{Figure 4}

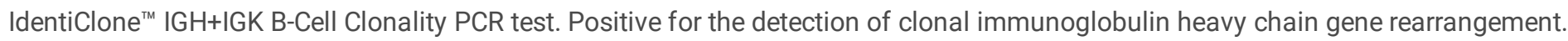
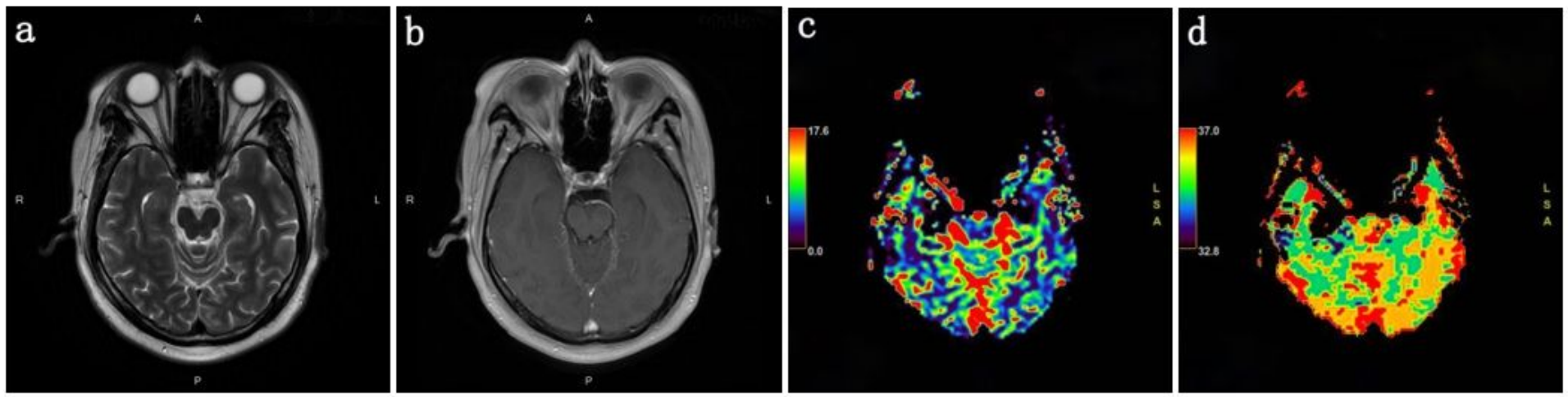

Figure 5

Follow up MRI shows no mass effect or abnormal enhancement, and PWI shows no hyperperfusion. 